\title{
Properties of stretchable lyocell yarns developed using modified ring spinning frame
}

See end of the paper for authors' affiliations SWATI SAHU

G.B. Pant University of Agriculture and Technology, PANTNAGAR

(UTTARAKHAND) INDIA

Email : sahuu.swatee611@gmail. com
ABSTRACT : Stretchable fabrics provide a better fitting in addition to unhindered body movement. These stretchable fabrics are usually developed using composite yarns esp. core spun yarns having spandex as core. In the current research, stretchable yarns were developed using spandex and lyocell fibres. Spandex filaments were used as a core and lyocell fibres were used as a covering sheath. Two deniers of spandex were used in order to study the effect of deniers on the properties of yarns. Core spun yarns were developed by modified ring spinning frame at constant drawing ratio i.e. 3 . Results of the study showed that presence of spandex, as well as change in its deniers, affected yarn count, tenacity, elongation and imperfection. However, breaking force and unevenness of yarns were remain unaffected by the presence of spandex as core in yarns.

KEY WORDS: Lyocell, Spandex, Ring spinning, Stretchable yarns

- HOW TO CITE THIS PAPER : Sahu, Swati and Goel, Alka (2017). Properties of stretchable lyocell yarns developed using modified ring spinning frame. Asian J. Home Sci., 12 (2) : 448-452, DOI: 10.15740/ HAS/AJHS/12.2/448-452. 